\title{
ORIGINAL RESEARCH \\ When Should "Pre" Carry as Much Weight in the Diabetes Comorbidity Debate? Insights From a Population-Based Survey
}

\author{
Negin Iranfar, $\mathrm{MPH}^{1}$; Tyler C. Smith, MS, $\mathrm{PhD}^{1}$
}

\begin{abstract}
Accessible Version: www.cdc.gov/pcd/issues/2018/17_0158.htm
Suggested citation for this article: Iranfar N, Smith TC. When Should "Pre" Carry as Much Weight in the Diabetes Comorbidity Debate? Insights From a Population-Based Survey. Prev Chronic Dis 2018;15:170158. DOI: https://doi.org/10.5888/pcd15.170158.
\end{abstract}

\section{PEER REVIEWED}

\section{Abstract}

\section{Introduction}

Estimates indicate that 86 million people in the United States fit the clinical definition of prediabetes, which contributes to the epidemic of nearly 2 million new diagnoses of type 2 diabetes mellitus each year. Effort has focused on preventing prediabetes from progressing to clinical diabetes. We investigated the sociodemographic, behavioral, and health factors in people diagnosed with diabetes or prediabetes and associated leading indicators and comorbidities.

\section{Methods}

We used Behavioral Risk Factor Surveillance System data from 2011 through $2015(\mathrm{~N}=1,699,754)$. All respondents aged 18 years or older with complete covariate data were included, differentiating between self-reported diagnosis of diabetes or prediabetes. Weighted univariate and multivariable logistic regression analyses of 28 variables were developed, with adjusted odds of diagnosis, and standardized coefficients were calculated to rank predictors for diabetes and prediabetes.

\section{Results}

Prevalence of prediabetes increased each year between 2011 and 2014. After adjusting for demographic, lifestyle, and health variables, the most significant predictors in magnitude of importance for prediabetes and diabetes were age and body mass index. Although adjusted odds for cardiovascular disease and kidney dis- ease were higher in respondents with diabetes than in those with prediabetes, respondents with prediabetes had higher adjusted odds of arthritis, depressive disorder, cancer, and chronic obstructive pulmonary disease.

\section{Conclusions}

Concurrent chronic diseases occur in people with prediabetes even at normal and overweight classifications. By identifying the conditions that are concomitant with diabetes, people with prediabetes can be provided with more rigorous and individualized treatments that can lead to better population health.

\section{Introduction}

Type 2 diabetes mellitus is a multifactorial chronic condition caused by defects in the metabolic system relating to insulin secretion and insulin resistance (1). According to the Centers for Disease Control and Prevention (CDC), an estimated 1.7 million incident cases of diabetes among Americans aged 20 years or older were reported in 2012, an equivalent of 4,657 daily cases (2). In 2014, the World Health Organization estimated that 387 million people worldwide have type 2 diabetes, with half as many cases still undiagnosed, projecting prevalence of type 2 diabetes at 592 million by 2035 (3).

The global epidemic of type 2 diabetes was predicted as early as 1971, as the result of a rapid increase in the prevalence of this disease among indigenous populations who adopted Western lifestyles $(4,5)$. Over the past 4 decades, many epidemiological studies demonstrated that the Western way of life has contributed to the increased prevalence of type 2 diabetes and its complications (6-8). Prediabetes is an early stage of dysglycemia that occurs before diagnosis of overt diabetes (9). According to CDC, as of 2014 , one in 3 adults older than 20 years ( 86 million people) had clinical prediabetes, with an estimated $8 \%$ to $12 \%$ diagnosed $(2,10)$; without any intervention to treat prediabetes through lifestyle modification, medication, or both, $5 \%$ to $10 \%$ of them will progress to type 2 diabetes each year, compared with $2 \%$ of nor- 
moglycemic people $(2,9,11)$. We used data from a large, representative, cross-sectional national survey to investigate the trend in type 2 diabetes and prediabetes from 2011 through 2015 in the United States.

\section{Methods}

\section{Population and data source}

Our study used a serial cross-sectional design using Behavioral Risk Factor Surveillance System (BRFSS) survey data from 2011 through 2015, for adults aged 18 or older with complete covariate data. BRFSS is an annual survey of randomly selected US residents contacted via telephone landline and cellular telephone in all 50 states, the District of Columbia, and 3 US territories, collected in either English or Spanish (12). Only 1 member of each household is surveyed, and the data are valid, reliable, and generalizable to the US population (13). The average response rate for the 2011 through 2015 BRFSS was 48\%. BRFSS data are publicly available and contain no personal identifiers; for this reason, this study was determined to be exempt from review by the National University Institutional Review Board.

\section{Variables}

\section{Measures}

We used data for respondents who self-reported a diagnosis of diabetes or prediabetes for whom there were full covariant data, based on their answers to 2 questions: 1) "Have you ever been told by a doctor or a health provider you have diabetes?"; and 2) "Ever been told by a doctor or a health provider you have prediabetes or borderline diabetes?" The aggregate 5-year affirmative responses for the questions were 1) $\mathrm{n}=215,441$ (12.7\%; weighted frequency $10.5 \%$ ) and 2) $n=63,567$ (3.7\%; weighted frequency $3 \%$ ). Women who self-reported having diabetes or prediabetes during pregnancy (gestational diabetes) were excluded from this study. Clinically, prediabetes is defined as the condition where glycemic parameters are above normal but below diabetes thresholds (14). The American Diabetes Association describes prediabetes as fasting plasma glucose (FPG) of 5.6 to $6.9 \mathrm{mmol} / \mathrm{L}$, referred to as an impaired fasting glucose level, and/or postload plasma glucose level of 7.8 to $11.1 \mathrm{mmol} / \mathrm{L}$, referred to as impaired glucose tolerance (14), or hemoglobin $A_{1 c}$ levels of $5.7 \%$ to $6.4 \%(15)$. We used data on respondents who self-reported a diagnosis of type 2 diabetes or prediabetes.

\section{Demographic and socioeconomic factors}

Self-reported age in years $(18-34,35-49,50-64$, or $\geq 65)$, marital status (married, never married, or other), military veteran status (yes or no), education level ( $\leq$ high school graduate, or some college and above), annual household income $(<\$ 15,000, \$ 15,000$ to
$<\$ 25,000, \$ 25,000$ to $<\$ 35,000, \$ 35,000$ to $<\$ 50,000$, or $\geq \$ 50,000$ ), consistent access to health provider (yes or no), routine annual checkup in the past 12 months (yes or no), race/ethnicity (white non-Hispanic, black non-Hispanic, Hispanic, or other), and sex. Data were also analyzed by geographic regions according to the 9 US Census Bureau designations (16): Northeast (New England division and Middle Atlantic division); Midwest (East North Central division and West North Central division); South (South Atlantic division, East South Central division, and West South Central division); and West (Mountain division and Pacific division) (for detailed list of states included in each division see https:/ /www2.census.gov/geo/pdfs/maps-data/maps/reference/us regdiv.pdf).

\section{Health variables}

Self-reported body mass index (BMI) was stratified into 4 categories: underweight (BMI $<18.5 \mathrm{~kg} / \mathrm{m}^{2}$ [weight in $\mathrm{kg}$ divided by height in $\left.\mathrm{m}^{2}\right]$ ), normal weight (BMI, 18.5-24.9), overweight (BMI 25.0-30.0), or obese (BMI >30.0). Other variables were general health condition (excellent/very good, good/fair, or poor); limited activity because of physical, mental, or emotional health (yes or no); and ever diagnosed with any of the following health conditions (yes or no): arthritis (eg, rheumatoid arthritis, gout, lupus, fibromyalgia), depressive disorder, asthma, chronic obstructive pulmonary disease (COPD) or pulmonary disease, kidney disease, cancer, or cardiovascular disease (CVD) (including chronic heart disease, heart attack, and stroke).

\section{Lifestyle variables}

Binary questions (yes or no) included smoking (100 or more cigarettes in lifetime), habitual drinking (men $>14$ drinks/week, women $>7$ drinks/week), and habitual exercise (any physical activity or exercise other than daily work-related routine in the past 30 days).

\section{Statistical analysis}

Descriptive and univariate analyses of the study population, prediabetes, and diabetes were conducted for all variables $(P<.05$ to assess significance). BRFSS weighting was used to adjust for differences in noncoverage and nonresponse in the sample to produce more generalizable estimates (17). Weighted multivariable logistic regression controlling for demographic, health, and lifestyle variables was used to obtain weighted and adjusted odds ratios (AORs) and 95\% confidence intervals (CIs) for each variable with respect to prediabetes and diabetes. A multicollinearity assessment, using a variance inflation factor, was performed, with values 4 and above indicating collinearity. Fisher scoring algorithm was used to calculate maximum likelihood and identify

\footnotetext{
The opinions expressed by authors contributing to this journal do not necessarily reflect the opinions of the U.S. Department of Health and Human Services, the Public Health Service, the Centers for Disease Control and Prevention, or the authors' affiliated institutions.
} 
the most influential factors in diabetes and prediabetes. Statistical analysis and data management were performed by using SAS software, version 9.4 (SAS Institute, Inc.).

\section{Results}

All year-to-year differences in frequency distribution for each variable for the study population $(\mathrm{N}=1,699,754)$ were significant, except for sex $(P=.19)$ (Table 1$)$. Most health conditions included in this study did not show a substantial increase in prevalence in the 5-year period, with 2 exceptions: depressive disorder increased from $16.9 \%$ to $18.1 \%$, and obesity increased from $28.4 \%$ to $29.8 \%$. A reduction in smoking occurred, from $45.4 \%$ in 2011 to $42.5 \%$ in 2015 . The prevalence of education beyond high school increased from $58.7 \%$ to $61.3 \%$; households with annual incomes from $\$ 15,000$ to less than $\$ 25,000$ decreased slightly from $17.6 \%$ to $15.8 \%$; households with annual incomes greater than $\$ 50,000$ increased from $44.9 \%$ to $49.9 \%$ (all values 2011 , 2015, respectively). During 2011 through 2015, regular annual physical checkups increased from $67.0 \%$ to $70.0 \%$; more than half of the population steadily reported a self-perceived health condition as excellent or very good (5-year average 52.6\%); $42.7 \%$ reported good to fair, and $4.6 \%$ reported poor general health $(P=$ .03) (Table 1).

Bivariate analysis of the respondents indicated that health condition, lifestyle, and demographic variables were significantly different for people reporting diabetes or prediabetes and the general population (Table 2). People diagnosed with diabetes and prediabetes were more likely to have obesity than the general public (54.0\% and $47.6 \%$, respectively, vs $29.1 \%$ ), be current or past smokers (52.7\% and 52.6\%, respectively, vs $43.7 \%$ ), have regular access to a physician $(92.8 \%$ and $88.3 \%$, respectively, vs $79.4 \%$ ), and receive a regular annual checkup $(86.0 \%$ and $79.2 \%$, respectively, vs $68.7 \%$ ). People with both diabetes and prediabetes reported less regular exercise $(62.8 \%$ and $70.4 \%$, respectively) compared with the general population (76.1\%) (Table 2). Geographically, the distribution of diabetes and prediabetes varied. Although reporting differences existed, prevalence of prediabetes was proportionately lower in Western areas and proportionately higher in the South (Table 2).

The 5-year aggregate study population was 50.5\% male and $49.5 \%$ female (Table 2). People diagnosed with prediabetes or diabetes were more likely to be white non-Hispanic than the survey population $(70.5 \%$ and $62.6 \%$, respectively, vs $68.1 \%)$. Similarly, people diagnosed with prediabetes or diabetes were more likely to be black non-Hispanic than the survey population $(15.2 \%$ and $16.2 \%$, respectively, vs $11.6 \%$ ) (Table 2 ). The risk of diabetes and prediabetes increased with age; respondents aged 18 to 34 years and 35 to 49 years had a higher proportion of prediabetes compared with diabetes (Table 2).

After adjusting for all health, lifestyle, and demographic variables, BMI and age remained most predictive in determining odds of prediabetes and diabetes. Adjusted odds of overweight among respondents with prediabetes (AOR, 1.61; 95\% CI, 1.54-1.68) and diabetes (AOR, 1.77; 95\% CI, 1.71-1.83) were similar. However, participants with obesity had higher adjusted odds of diabetes (AOR, 3.66; 95\% CI, 3.55-3.78) than prediabetes (AOR, 2.47; 95\% CI, 2.36-2.58). The most significant predictors of prediabetes, in magnitude of importance, were obesity and age, which were also predictors for diabetes, although the order of magnitude was reversed, with age followed by obesity. Multicollinearity assessment using a variance inflation factor indicated no collinearity among the variables (collinearity $<4$ ).

Adjusted odds for prediabetes showed a steady year-to-year increase from 2.4 in 2012 to 3.5 in 2014 (2015 data missing), yet diabetes prevalence remained steady for years 2011 through 2015 (Table 3). Among the 8 health conditions in this study, the unadjusted prevalence of CVD and kidney disease was higher among those with diabetes than among those with prediabetes (Table 2). After adjusting for all other variables, the adjusted odds for CVD and kidney disease remained significantly higher among those with diabetes than those with prediabetes: with CVD and diabetes, AOR of $1.56(95 \% \mathrm{CI}, 1.52-1.60)$, and with prediabetes, AOR of 1.06 (95\% CI, 1.01-1.10); kidney disease with diabetes, AOR of 1.97 (95\% CI, 1.88-2.06), and with prediabetes, AOR of 0.84 (95\% CI, 0.78-0.91) (Table 3). For the other 5 chronic health conditions, the percentage prevalences and AORs for those with prediabetes and those with diabetes were comparable or slightly higher (Tables 2 and 3).

The aggregate prevalence of chronic diseases for the 5-year period 2011 through 2015 was calculated in the general population and for prediabetes and diabetes (Figure). All values were significant (data not shown). The unadjusted bivariate analysis indicated that the prevalence of chronic diseases was higher among respondents with obesity who had diabetes. A higher percentage of people with prediabetes was found in the underweight (not shown), normal, and overweight categories (Figure).

The opinions expressed by authors contributing to this journal do not necessarily reflect the opinions of the U.S. Department of Health and Human Services, the Public Health Service, the Centers for Disease Control and Prevention, or the authors' affiliated institutions. 
Normal Weight

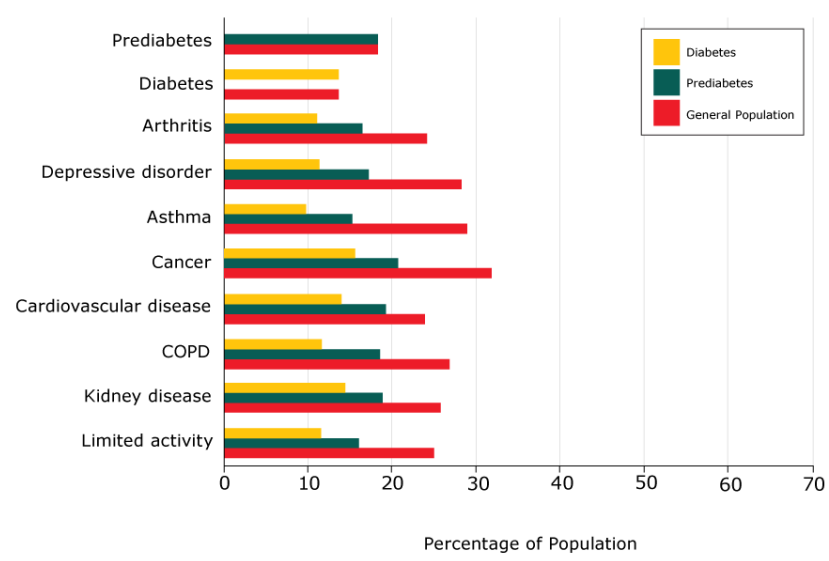

B
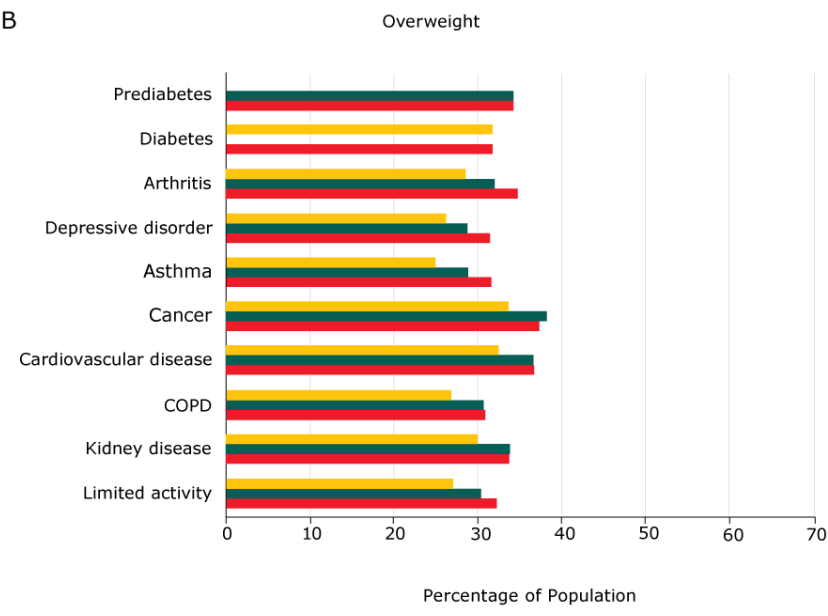

C

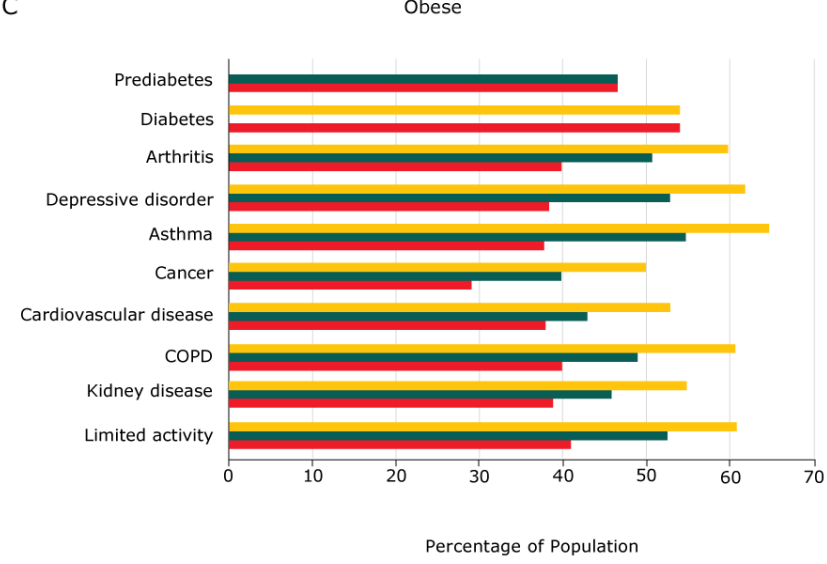

Figure. Unadjusted bivariate analysis of prevalence of chronic diseases among persons with prediabetes and diabetes by body mass index category, Behavioral Risk Factor Surveillance System, 2011-2015. Abbreviation: COPD, chronic obstructive pulmonary disease.

\section{Discussion}

Prediabetes is an early indicator of diabetes and contributes to the worldwide pandemic $(3,7)$. Between $5 \%$ and $10 \%$ of people with prediabetes are estimated to progress annually to diabetes, depending on race/ethnicity and the detailed pathogenesis of their prediabetes $(2,9,11)$. Of the estimated 86 million individuals with prediabetes in the United States, only $8 \%$ to $11.6 \%$, or between 7 and 10 million individuals, have received a diagnosis and are aware of their prediabetes condition. Furthermore, a consistent set of chronic diseases associated with diabetes is seen in people with diagnosed prediabetes, even at lower BMI. This is alarming and may indicate a greater need for more rigorous diagnosis of prediabetes. It also raises the question of whether current treatments and interventions for prediabetes, although successful in delaying progression to diabetes, sufficiently address other chronic diseases concomitant with prediabetes. Many of the chronic health conditions included in this study are closely related to obesity, and are most prevalent among populations with obesity who have diabetes (Figure). However, the increasing frequency of these conditions among people with diagnosed prediabetes at lower BMI (normal and overweight) may signify an unwelcome trend of increased risk of comorbidities at lower BMI in prediabetes.

In an extensive meta-analysis of 16 prospective cohort studies that included more than 890,000 participants, Huang et al found that people with prediabetes at baseline had a significantly increased risk of cancer (18). Additional literature has associated increased risk for kidney disease (19), CVD (20), and arthritis (21) with prediabetes. Risk factors for diabetes and prediabetes (age, obesity, and physical inactivity) have been documented $(22,23)$ and are confirmed in our study, with age and BMI being most highly predictive for both conditions. Conversely, regular annual checkups and access to physicians had a protective effect on diabetes. Accordingly, the focus has been on changing lifestyle habits among people with prediabetes and diabetes and using medication $(24,25)$.

Several international trials have demonstrated the reversion from prediabetes to normoglycemia, based on lifestyle and drug-based interventions. The Finnish Diabetes Prevention Study reported average weight loss of $4.2 \mathrm{~kg}$ during a 3-year period using lifestyle intervention and medication (26). However, there are concerns that treating prediabetes with medication is an overtreatment of a nondisease condition and should be approached only in cases with

\footnotetext{
The opinions expressed by authors contributing to this journal do not necessarily reflect the opinions of the U.S. Department of Health and Human Services, the Public Health Service, the Centers for Disease Control and Prevention, or the authors' affiliated institutions.
} 
other comorbidities, such as heart disease (27). One of the many debates about treatments of prediabetes is the question of whether the focus should be on reversing the condition or simply delaying development of diabetes. Studies suggest that prolonged duration of prediabetes can result in both microvascular and macrovascular complications of diabetes, even in the absence of overt development of diabetes (11). Our results concur with such concerns and add to the body of knowledge addressing the possible public health implications of an extended long-term prediabetes condition.

Our study has limitations. First, we used self-reported data, which were not confirmed by medical records or other health history information. Self-reported data may not reflect the continuum of disease and may better be assessed with a simple functional health assessment, which was outside the limits of this study. Furthermore, the survey questions were designed as "Have you ever...," eliminating any distinction between prevalence and those who may have reverted to normoglycemia, resulting in possible overestimation of current prevalence. Second, self-reported diabetes does not distinguish between type 1 and type 2 diabetes; however, it is generally accepted that more than $90 \%$ of diabetes in the United States is type 2 (15). Although limitations are inherent in the depth and accuracy of any self-reported survey data, it nonetheless allows us to identify consistencies in variables common in both diabetes and prediabetes. Third, although BRFSS data encompass a large crosssection of the population, including both cellular telephone and landline telephone surveys since 2011, they still exclude or could underrepresent certain groups and races/ethnicities with language limitations, telephone access limitations, or those who are institutionalized. Fourth, reporting frequencies on prediabetes-specific questions has been inconsistent among the 50 states and the District of Columbia; some states did not report on that survey question during 1 or more of the 5 periods of this study, and in particular 39 states did not collect data on prediabetes for the 2015 survey year. As such we expect the prevalence of diagnosed prediabetes to be an underestimation and not valid for geographic region comparisons. This has also precluded us from estimating prediabetes prevalence for 2015. Another possible bias is that prediabetes overall is more prevalent than diagnosed prediabetes. As such, there may be a differential misclassification for diagnosed prediabetes with concurrent comorbidities. More prospective data may provide an excellent source to isolate the effect size of any such bias. Fifth, the nature of the cross-sectional survey prevents any extrapolation of causal relationships between the various health conditions used in this study and diabetes or prediabetes. Therefore, it cannot be determined if impaired glucose metabolism is responsible for other health conditions or perhaps caused by some combination of comorbidities included in this study. However, it is generally accepted that obesity is a common cause for most chronic health conditions. Furthermore, the self-reported diagnosis of prediabetes is likely an underestimation of actual prediabetes in the United States, because the American Diabetes Association only recommends screening for this condition starting at age 45, and then only if there are other health factors (15); similarly, adults younger than 50 may not be aware that they have diabetes. Lastly, BRFSS does not include any questions about frequency of testing the blood glucose level, glycated hemoglobin $A_{1 c}$, or any other screening or treatments of those diagnosed with prediabetes. As such, it is unknown if people with diagnosed prediabetes are getting the same or similar care as people diagnosed with diabetes.

Although much attention has been given to diagnosis of at-risk populations at the stage of prediabetes to reduce incidence of diabetes, efforts are focused on preventing prediabetes from progressing to diabetes. Implied in this attitude is the view that prediabetes has lower rates of morbidity compared with diabetes. However, the validity of this assumption is not clear. This study highlights that many chronic disease conditions are present at high rates in prediabetes and that a prolonged period of prediabetes does not necessarily reduce the risk of certain comorbidities compared with diabetes. Our results suggest that there may even be an increased risk at lower BMI among people with prediabetes to present with other chronic comorbid health conditions. In light of potential comorbidities that may occur in this at-risk population, substantial effort should be considered to identify prediabetes at a lower BMI and younger age, where rigorous attempts to reverse prediabetes to normoglycemia could prove far more beneficial in promoting public health.

\section{Acknowledgments}

The views expressed in this article are those of the authors and do not reflect the official policy or position of National University. We thank the BRFSS team for surveying, cleaning, and managing these data and for putting them forward for research purposes as a public use data file. We are indebted to the BRFSS participants, without whom these analyses would not be possible.

The authors have no financial relationships to disclose relevant to this article and have not been funded to conduct this research.

\section{Author Information}

Corresponding Author: Negin Iranfar, MPH, Department of Community Health, School of Health and Human Services, National University, 3678 Aero Ct, San Diego, CA 92123. Telephone: 858-663-2304. Email: Negin.Iranfar@natuniv.edu.

The opinions expressed by authors contributing to this journal do not necessarily reflect the opinions of the U.S. Department of Health and Human Services, the Public Health Service, the Centers for Disease Control and Prevention, or the authors' affiliated institutions. 
Author Affiliations: ${ }^{1}$ National University, San Diego, California.

\section{References}

1. Ozougwu JC, Obimba KC, Belonwu CD, Unakalamba CB. The pathogenesis and pathophysiology of type 1 and type 2 diabetes mellitus. Journal of Physiology and Pathophysiology 2013;4(4):46-57.

2. Centers for Disease Control and Prevention.National diabetes statistics report: estimates of diabetes and its burden in the United States, 2014. https://www.cdc.gov/diabetes/pdfs/data/ 2014-report-estimates-of-diabetes-and-its-burden-in-theunited-states.pdf. Accessed February 20, 2018.

3. World Health Organization. WHO global status report on noncommunicable diseases, 2010. Geneva: World Health Organization; 2011.

4. Bennett PH, Burch TA, Miller M. Diabetes mellitus in American (Pima) Indians. Lancet 1971;298(7716):125-8.

5. West KM, Kalbfleisch JM. Influence of nutritional factors on prevalence of diabetes. Diabetes 1971;20(2):99-108.

6. Chen L, Magliano DJ, Zimmet PZ. The worldwide epidemiology of type 2 diabetes mellitus - present and future perspectives. Nat Rev Endocrinol 2012;8(4):228-36.

7. Kharroubi AT, Darwish HM. Diabetes mellitus: the epidemic of the century. World J Diabetes 2015;6(6):850-67.

8. King GL, McNeely MJ, Thorpe LE, Mau ML, Ko J, Liu LL, et al. Understanding and addressing unique needs of diabetes in Asian Americans, native Hawaiians, and Pacific Islanders. Diabetes Care 2012;35(5):1181-8.

9. Tabák AG, Herder C, Rathmann W, Brunner EJ, Kivimäki M. Prediabetes: a high-risk state for diabetes development. Lancet 2012;379(9833):2279-90.

10. Campbell TJ, Alberga A, Rosella LC. The impact of access to health services on prediabetes awareness: a population-based study. Prev Med 2016;93:7-13.

11. Perreault L, Færch K. Approaching pre-diabetes. J Diabetes Complications 2014;28(2):226-33.

12. Centers for Disease Control and Prevention. Behavioral Risk Factor Surveillance System. https://www.cdc.gov/brfss/data_ tools.htm. Accessed October 10, 2016.

13. Mokdad AH. The Behavioral Risk Factors Surveillance System: past, present, and future. Annu Rev Public Health 2009;30(1):43-54.

14. American Diabetes Association. Diagnosis and classification of diabetes mellitus. Diabetes Care 2004;27(Suppl 1):S5-10.

15. American Diabetes Association. Diagnosis and classification of diabetes mellitus. Diabetes Care 2010;33(Suppl 1):S62-9.
16. US Census Bureau. Census regions and divisions of the United States; 2014. https://www2.census.gov/geo/pdfs/maps-data/ maps/reference/us_regdiv.pdf. Accessed September 10, 2016.

17. Pierannunzi $\mathrm{C}, \overline{\mathrm{Hu}} \mathrm{SS}$, Balluz L. A systematic review of publications assessing reliability and validity of the Behavioral Risk Factor Surveillance System (BRFSS), 2004-2011. BMC Med Res Methodol 2013;13(1):49.

18. Huang Y, Cai X, Qiu M, Chen P, Tang H, Hu Y, et al. Prediabetes and the risk of cancer: a meta-analysis. Diabetologia 2014;57(11):2261-9.

19. Echouffo-Tcheugui JB, Narayan KM, Weisman D, Golden SH, Jaar BG. Association between prediabetes and risk of chronic kidney disease: a systematic review and meta-analysis. Diabet Med 2016;33(12):1615-24.

20. Perreault L, Temprosa M, Mather KJ, Horton E, Kitabchi A, Larkin M, et al.; Diabetes Prevention Program Research Group. Regression from prediabetes to normal glucose regulation is associated with reduction in cardiovascular risk: results from the Diabetes Prevention Program outcomes study. Diabetes Care 2014;37(9):2622-31.

21. Origuchi T, Yamaguchi S, Inoue A, Kazaura Y, Matsuo N, Abiru N, et al. Increased incidence of pre-diabetes mellitus at a department of rheumatology: a retrospective study. Mod Rheumatol 2011;21(5):495-9.

22. Mokdad AH, Bowman BA, Ford ES, Vinicor F, Marks JS, Koplan JP. The continuing epidemics of obesity and diabetes in the United States. JAMA 2001;286(10):1195-200.

23. Narayan KM, Boyle JP, Thompson TJ, Sorensen SW, Williamson DF. Lifetime risk for diabetes mellitus in the United States. JAMA 2003;290(14):1884-90.

24. Diabetes Prevention Program Research Group. The 10-year cost-effectiveness of lifestyle intervention or metformin for diabetes prevention: an intent-to-treat analysis of the DPP/ DPPOS. Diabetes Care 2012;35(4):723-30. Erratum in Diabetes Care 2013;36(12):4173-5.

25. Bergman M. Inadequacies of current approaches to prediabetes and diabetes prevention. Endocrine 2013;44(3):623-33.

26. Tuomilehto J, Lindström J, Eriksson JG, Valle TT, Hämäläinen $\mathrm{H}$, Ilanne-Parikka $\mathrm{P}$, et al.; Finnish Diabetes Prevention Study Group. Prevention of type 2 diabetes mellitus by changes in lifestyle among subjects with impaired glucose tolerance. N Engl J Med 2001;344(18):1343-50.

27. Yudkin JS, Montori VM. The epidemic of pre-diabetes: the medicine and the politics. BMJ 2014;349:g4485. Erratum in BMJ 2014;349:g4683.

\footnotetext{
The opinions expressed by authors contributing to this journal do not necessarily reflect the opinions of the U.S. Department of Health and Human Services, the Public Health Service, the Centers for Disease Control and Prevention, or the authors' affiliated institutions.
} 


\section{Tables}

Table 1. Characteristics of Respondents ( $\mathrm{N}=1,699,754)$ Who Responded Yes for Condition or Behavior, Behavioral Risk Factor Surveillance System, 2011-2015

\begin{tabular}{|c|c|c|c|c|c|c|}
\hline Characteristic & $2011, \%$ & $2012, \%$ & $2013, \%$ & $2014, \%$ & $2015, \%$ & $P$ Value $^{\mathrm{b}}$ \\
\hline \multicolumn{7}{|c|}{ Health Condition } \\
\hline \multicolumn{7}{|l|}{ Chronic condition } \\
\hline Arthritis $^{c}$ & 25.4 & 26.2 & 26.1 & 26.6 & 25.7 & $<.001$ \\
\hline Depressive disorder & 16.9 & 17.1 & 18.0 & 18.3 & 18.1 & $<.001$ \\
\hline Asthma & 13.3 & 13.0 & 13.8 & 13.5 & 13.6 & $<.001$ \\
\hline Cancer $^{d}$ & 11.6 & 11.3 & 11.8 & 11.6 & 12.1 & $<.001$ \\
\hline Cardiovascular disease $^{\mathrm{e}}$ & 8.4 & 8.7 & 8.8 & 8.9 & 8.6 & $<.001$ \\
\hline Chronic obstructive pulmonary disease $(\mathrm{COPD})^{f}$ & 6.4 & 6.5 & 6.6 & 6.8 & 6.6 & .001 \\
\hline Kidney disease & 2.5 & 2.7 & 2.7 & 2.8 & 2.7 & .01 \\
\hline Limited activity $^{\mathrm{g}}$ & 23.8 & 20.5 & 20.0 & 21.0 & 20.7 & $<.001$ \\
\hline \multicolumn{7}{|l|}{ General health } \\
\hline Excellent, very good & 52.6 & 52.6 & 52.5 & 52.8 & 52.8 & \multirow{3}{*}{.03} \\
\hline Good, fair & 42.8 & 42.6 & 42.9 & 42.5 & 42.8 & \\
\hline Poor & 4.6 & 4.8 & 4.6 & 4.7 & 4.4 & \\
\hline \multicolumn{7}{|l|}{$\mathrm{BMI}^{\mathrm{h}}$} \\
\hline Underweight & 1.6 & 1.7 & 1.7 & 1.8 & 1.5 & \multirow{4}{*}{$<.001$} \\
\hline Normal & 33.9 & 33.7 & 33.2 & 32.8 & 32.5 & \\
\hline Overweight & 36.1 & 36.1 & 35.9 & 35.6 & 36.2 & \\
\hline Obese & 28.4 & 28.6 & 29.2 & 29.8 & 29.8 & \\
\hline \multicolumn{7}{|c|}{ Lifestyle } \\
\hline Smokingi & 45.4 & 44.2 & 43.5 & 42.8 & 42.5 & $<.001$ \\
\hline Consume alcohol regularly & 6.8 & 6.2 & 6.3 & 6.2 & 6.2 & $<.001$ \\
\hline Exercise regularly ${ }^{\mathrm{k}}$ & 75.4 & 77.8 & 74.7 & 77.5 & 75.2 & $<.001$ \\
\hline
\end{tabular}

${ }^{a}$ Percentages are weighted.

${ }^{\mathrm{b}} P$ values based on Pearson $\mathrm{X}^{2}$ test of association; significant at $P<.05$.

${ }^{\mathrm{c}}$ Ever been diagnosed with arthritis (eg, rheumatoid arthritis, gout, lupus, fibromyalgia).

${ }^{d}$ Ever been diagnosed with any type of cancer.

e Ever been diagnosed with chronic heart disease, heart attack, or stroke.

${ }^{f}$ Ever been diagnosed with COPD or pulmonary disease.

g Limited in any way in any activity because of physical, mental, or emotional problems.

${ }^{\mathrm{h}}$ Body mass index $\left(\mathrm{BMI}, \mathrm{kg} / \mathrm{m}^{2}\right.$ ) is categorized as underweight (BMI <18.5), normal weight (BMI, 18.5-24.9), overweight (BMI, 25.0-30.0), or obese (BMI >30.0).

i Smoked more than 100 cigarettes during lifetime.

${ }^{j}$ Men having more than 14 drinks per week and women having more than 7 drinks per week.

${ }^{k}$ During the past month, other than for your regular job, did you participate in any physical activities or exercises such as running, calisthenics, golf, gardening, or walking for exercise.

' Separated, widowed, never married, a member of an unmarried couple.

${ }^{m}$ Geographic regions based on US Census (a detailed list of states included in each division is available at https://www2.census.gov/geo/pdfs/maps-data/maps/ reference/us_regdiv.pdf). 
(continued)

Table 1. Characteristics of Respondents $(\mathrm{N}=1,699,754)$ Who Responded Yes for Condition or Behavior, Behavioral Risk Factor Surveillance System, 2011-2015

\begin{tabular}{|c|c|c|c|c|c|c|}
\hline Characteristic & $2011, \%$ & $2012, \%$ & $2013, \%$ & $2014, \%$ & $2015, \%$ & $P$ Value $^{\mathrm{b}}$ \\
\hline \multicolumn{7}{|c|}{ Demographics/socioeconomics } \\
\hline \multicolumn{7}{|l|}{ Military status } \\
\hline Veteran & 12.2 & 12.0 & 11.8 & 12.5 & 12.2 & \multirow{2}{*}{$<.001$} \\
\hline Nonveteran & 87.8 & 88.0 & 88.2 & 87.5 & 87.8 & \\
\hline \multicolumn{7}{|l|}{ Education level } \\
\hline High school graduate or less & 41.3 & 40.8 & 40.2 & 40.1 & 38.7 & \multirow{2}{*}{$<.001$} \\
\hline Some college and above & 58.7 & 59.2 & 59.8 & 59.9 & 61.3 & \\
\hline \multicolumn{7}{|l|}{ Marital status } \\
\hline Married & 55.3 & 54.1 & 56.1 & 55.3 & 55.4 & \multirow{3}{*}{$<.001$} \\
\hline Never married & 24.0 & 25.2 & 22.7 & 23.6 & 23.2 & \\
\hline Other' & 20.7 & 20.7 & 21.2 & 21.2 & 21.3 & \\
\hline \multicolumn{7}{|l|}{ Sex } \\
\hline Male & 50.6 & 50.5 & 50.3 & 50.4 & 50.9 & \multirow{2}{*}{.19} \\
\hline Female & 49.4 & 49.5 & 49.7 & 49.6 & 49.1 & \\
\hline \multicolumn{7}{|l|}{ Race/ethnicity } \\
\hline White non-Hispanic & 69.7 & 67.5 & 67.6 & 68.1 & 67.5 & \multirow{4}{*}{$<.001$} \\
\hline Black non-Hispanic & 11.2 & 11.8 & 11.5 & 11.8 & 11.4 & \\
\hline Hispanic & 12.1 & 13.2 & 13.5 & 12.7 & 13.5 & \\
\hline Other & 7.0 & 7.5 & 7.3 & 7.3 & 7.6 & \\
\hline \multicolumn{7}{|l|}{ Income, $\$$} \\
\hline$<15,000$ & 11.9 & 12.2 & 11.9 & 11.4 & 10.2 & \multirow{5}{*}{$<.001$} \\
\hline 15,000 to $<25,000$ & 17.6 & 17.3 & 17.0 & 16.9 & 15.8 & \\
\hline 25,000 to $<35,000$ & 11.4 & 11.0 & 10.8 & 10.7 & 10.3 & \\
\hline 35,000 to $<50,000$ & 14.3 & 14.4 & 14.3 & 13.9 & 13.8 & \\
\hline$\geq 50,000$ & 44.9 & 45.1 & 46.0 & 47.1 & 49.9 & \\
\hline \multicolumn{7}{|l|}{ Health care access } \\
\hline
\end{tabular}

${ }^{\text {a }}$ Percentages are weighted.

${ }^{\mathrm{b}} P$ values based on Pearson $x^{2}$ test of association; significant at $P<.05$.

${ }^{\mathrm{C}}$ Ever been diagnosed with arthritis (eg, rheumatoid arthritis, gout, lupus, fibromyalgia).

${ }^{\mathrm{d}}$ Ever been diagnosed with any type of cancer.

${ }^{e}$ Ever been diagnosed with chronic heart disease, heart attack, or stroke.

${ }^{f}$ Ever been diagnosed with COPD or pulmonary disease.

${ }^{g}$ Limited in any way in any activity because of physical, mental, or emotional problems.

${ }^{\mathrm{h}}$ Body mass index $\left(\mathrm{BMI}, \mathrm{kg} / \mathrm{m}^{2}\right.$ ) is categorized as underweight (BMI <18.5), normal weight (BMI, 18.5-24.9), overweight (BMI, 25.0-30.0), or obese (BMI >30.0).

i Smoked more than 100 cigarettes during lifetime.

${ }^{j}$ Men having more than 14 drinks per week and women having more than 7 drinks per week.

${ }^{k}$ During the past month, other than for your regular job, did you participate in any physical activities or exercises such as running, calisthenics, golf, gardening, or walking for exercise.

'Separated, widowed, never married, a member of an unmarried couple.

${ }^{m}$ Geographic regions based on US Census (a detailed list of states included in each division is available at https://www2.census.gov/geo/pdfs/maps-data/maps/ reference/us_regdiv.pdf).

The opinions expressed by authors contributing to this journal do not necessarily reflect the opinions of the U.S. Department of Health and Human Services, the Public Health Service, the Centers for Disease Control and Prevention, or the authors' affiliated institutions. 
(continued)

Table 1. Characteristics of Respondents $(\mathrm{N}=1,699,754)$ Who Responded Yes for Condition or Behavior, Behavioral Risk Factor Surveillance System, 2011-2015

\begin{tabular}{|c|c|c|c|c|c|c|}
\hline Characteristic & $2011, \%$ & $2012, \%$ & $2013, \%$ & $2014, \%$ & $2015, \%$ & $P$ Value $^{\mathrm{b}}$ \\
\hline Consistent access to health provider & 80.1 & 79.4 & 78.1 & 79.0 & 80.4 & $<.001$ \\
\hline Annual health checkup & 67.0 & 67.6 & 68.5 & 70.1 & 70.0 & $<.001$ \\
\hline \multicolumn{7}{|l|}{ Age, y } \\
\hline $18-34$ & 27.0 & 27.4 & 26.9 & 27.3 & 26.8 & \multirow{4}{*}{$<.001$} \\
\hline $35-49$ & 27.9 & 26.6 & 25.7 & 25.2 & 25.1 & \\
\hline $50-64$ & 27.5 & 27.9 & 28.6 & 28.3 & 28.2 & \\
\hline$\geq 65$ & 17.5 & 18.1 & 18.8 & 19.2 & 19.8 & \\
\hline \multicolumn{7}{|l|}{ Geographic region $^{\mathrm{m}}$} \\
\hline Midwest: East North Central division & 16.2 & 15.9 & 16.0 & 16.2 & 16.0 & \multirow{9}{*}{$<.001$} \\
\hline Midwest: West North Central division & 6.9 & 6.8 & 6.4 & 6.9 & 6.8 & \\
\hline South: South Atlantic division & 19.6 & 19.7 & 19.7 & 20.0 & 19.9 & \\
\hline South: East South Central division & 5.7 & 5.9 & 5.5 & 6.0 & 5.8 & \\
\hline South: West South Central division & 11.3 & 11.5 & 11.1 & 11.2 & 11.3 & \\
\hline Northeast: New England division & 4.8 & 4.7 & 4.7 & 4.7 & 4.4 & \\
\hline Northeast: Middle Atlantic division & 12.9 & 12.7 & 12.9 & 13.2 & 12.8 & \\
\hline West: Mountain division & 7.1 & 7.0 & 7.2 & 7.2 & 7.1 & \\
\hline West: Pacific division & 15.5 & 15.8 & 16.4 & 14.6 & 15.9 & \\
\hline
\end{tabular}

${ }^{a}$ Percentages are weighted.

${ }^{\mathrm{b}} P$ values based on Pearson $\mathrm{X}^{2}$ test of association; significant at $P<.05$.

${ }^{\mathrm{c}}$ Ever been diagnosed with arthritis (eg, rheumatoid arthritis, gout, lupus, fibromyalgia).

${ }^{\mathrm{d}}$ Ever been diagnosed with any type of cancer.

${ }^{\mathrm{e}}$ Ever been diagnosed with chronic heart disease, heart attack, or stroke.

${ }^{f}$ Ever been diagnosed with COPD or pulmonary disease.

${ }^{g}$ Limited in any way in any activity because of physical, mental, or emotional problems.

${ }^{\mathrm{h}}$ Body mass index $\left(\mathrm{BMI}, \mathrm{kg} / \mathrm{m}^{2}\right.$ ) is categorized as underweight (BMI <18.5), normal weight (BMI, 18.5-24.9), overweight (BMI, 25.0-30.0), or obese (BMI >30.0).

'Smoked more than 100 cigarettes during lifetime.

${ }^{j}$ Men having more than 14 drinks per week and women having more than 7 drinks per week.

${ }^{k}$ During the past month, other than for your regular job, did you participate in any physical activities or exercises such as running, calisthenics, golf, gardening, or walking for exercise.

'Separated, widowed, never married, a member of an unmarried couple.

${ }^{m}$ Geographic regions based on US Census (a detailed list of states included in each division is available at https://www2.census.gov/geo/pdfs/maps-data/maps/ reference/us_regdiv.pdf). 
Table 2. Characteristics of Respondents That Have Ever Been Diagnosed with Prediabetes $(N=63,567)$ or Diabetes $(N=215,441)$, Behavioral Risk Factor Surveillance System, 2011-2015

\begin{tabular}{|c|c|c|c|c|c|c|}
\hline Characteristic & General Population, \% & $P$ Value $^{\mathrm{b}}$ & Prediabetes, $\%$ & $P$ Value $^{\mathrm{b}}$ & Diabetes, \% & $P$ Value $^{\mathrm{b}}$ \\
\hline \multicolumn{7}{|l|}{ Survey year } \\
\hline 2011 & 19.4 & \multirow{5}{*}{$<.001$} & 1.4 & \multirow{5}{*}{$<.001$} & 10.0 & \multirow{5}{*}{$<.001$} \\
\hline 2012 & 20.9 & & 3.3 & & 10.4 & \\
\hline 2013 & 19.9 & & 3.7 & & 10.6 & \\
\hline 2014 & 20.5 & & 4.8 & & 10.8 & \\
\hline 2015 & 19.2 & & $-{ }^{c}$ & & 10.9 & \\
\hline \multicolumn{7}{|c|}{ Health Condition } \\
\hline \multicolumn{7}{|l|}{ Chronic condition } \\
\hline Arthritis $^{d}$ & 26.0 & $<.001$ & 43.6 & $<.001$ & 49.3 & $<.001$ \\
\hline Depressive disorder & 17.7 & $<.001$ & 27.5 & $<.001$ & 26.1 & $<.001$ \\
\hline Asthma & 13.4 & $<.001$ & 17.7 & $<.001$ & 17.6 & $<.001$ \\
\hline Cancer ${ }^{\mathrm{e}}$ & 11.7 & $<.001$ & 17.3 & $<.001$ & 19.3 & $<.001$ \\
\hline Cardiovascular disease $^{f}$ & 8.7 & .002 & 15.4 & $<.001$ & 25.3 & $<.001$ \\
\hline $\begin{array}{l}\text { Chronic obstructive pulmonary disease } \\
\text { (COPD) }^{\mathrm{g}}\end{array}$ & 6.6 & $<.001$ & 12.7 & $<.001$ & 14.1 & $<.001$ \\
\hline Kidney disease & 2.7 & $<.01$ & 3.7 & $<.001$ & 8.9 & $<.001$ \\
\hline Limited activity ${ }^{\mathrm{h}}$ & 21.2 & $<.001$ & 33.5 & $<.001$ & 41.4 & $<.001$ \\
\hline \multicolumn{7}{|l|}{ General health } \\
\hline Excellent, Very good & 52.6 & \multirow{3}{*}{.03} & 35.8 & \multirow{3}{*}{$<.001$} & 19.0 & \multirow{3}{*}{$<.001$} \\
\hline Good, Fair & 42.7 & & 56.4 & & 65.5 & \\
\hline Poor & 4.6 & & 7.8 & & 15.5 & \\
\hline \multicolumn{7}{|l|}{ BMI $^{\prime}$} \\
\hline Underweight & 1.7 & \multirow{2}{*}{$<.001$} & 0.9 & \multirow{2}{*}{$<.001$} & 0.6 & \multirow{2}{*}{$<.001$} \\
\hline Normal & 33.2 & & 17.3 & & 13.7 & \\
\hline
\end{tabular}

${ }^{a}$ Values reflect weighted percentages affirmative for condition or behavior.

${ }^{\mathrm{b}} P$ values based on Pearson $\mathrm{x}^{2}$ test of association; significant at $P<.05$.

${ }^{c}$ Prediabetes prevalence for 2015 is not included because a large number of states did not report on prediabetes.

${ }^{\mathrm{d}}$ Ever been diagnosed with arthritis (eg, rheumatoid arthritis, gout, lupus, fibromyalgia).

${ }^{\mathrm{e}}$ Ever been diagnosed with any type of cancer.

${ }^{f}$ Ever been diagnosed with chronic heart disease, heart attack, or stroke.

${ }^{g}$ Ever been diagnosed with COPD or pulmonary disease.

${ }^{\mathrm{h}}$ Limited in any way in any activity because of physical, mental, or emotional problems.

i Body mass index (BMI, kg/m²) is categorized as underweight (BMI <18.5), normal weight (BMI 18.5-24.9), overweight (BMI 25.0-30.0), or obese (BMI >30.0).

${ }^{j}$ Smoked more than 100 cigarettes during lifetime.

${ }^{\mathrm{k}}$ Men having more than 14 drinks per week and women having more than 7 drinks per week.

'During the past month, other than for your regular job, did you participate in any physical activities or exercises such as running, calisthenics, golf, gardening, or walking for exercise.

${ }^{m}$ Separated, widowed, never married, a member of an unmarried couple.

${ }^{n}$ Geographic regions based on United States Census (a detailed list of states included in each division is available at https://www2.census.gov/geo/pdfs/mapsdata/maps/reference/us_regdiv.pdf).

The opinions expressed by authors contributing to this journal do not necessarily reflect the opinions of the U.S. Department of Health and Human Services, the Public Health Service, the Centers for Disease Control and Prevention, or the authors' affiliated institutions. 
(continued)

Table 2. Characteristics of Respondents That Have Ever Been Diagnosed with Prediabetes $(N=63,567)$ or Diabetes $(N=215,441)$, Behavioral Risk Factor Surveillance System, 2011-2015 ${ }^{\mathrm{a}}$

\begin{tabular}{|c|c|c|c|c|c|c|}
\hline Characteristic & General Population, \% & $P$ Value $^{\mathrm{b}}$ & Prediabetes, \% & $P$ Value $^{\mathrm{b}}$ & Diabetes, \% & $P$ Value $^{\mathrm{b}}$ \\
\hline Overweight & 36.0 & & 34.2 & & 31.7 & \\
\hline Obese & 29.1 & & 47.6 & & 54.0 & \\
\hline \multicolumn{7}{|c|}{ Lifestyle } \\
\hline Smoking & 43.7 & $<.001$ & 52.6 & $<.001$ & 52.7 & $<.001$ \\
\hline Consume alcohol regularly ${ }^{k}$ & 6.3 & $<.001$ & 5.4 & $<.001$ & 2.6 & $<.001$ \\
\hline Exercise regularly $^{\prime}$ & 76.1 & $<.001$ & 70.4 & $<.001$ & 62.8 & $<.001$ \\
\hline \multicolumn{7}{|c|}{ Demographics/socioeconomics } \\
\hline \multicolumn{7}{|l|}{ Military status } \\
\hline Veteran & 12.2 & \multirow{2}{*}{$<.001$} & 16.1 & \multirow{2}{*}{$<.001$} & 18.7 & \multirow{2}{*}{$<.001$} \\
\hline Nonveteran & 87.8 & & 83.9 & & 81.3 & \\
\hline \multicolumn{7}{|l|}{ Education level } \\
\hline High school graduate or less & 40.2 & \multirow{2}{*}{$<.001$} & 44.4 & \multirow{2}{*}{$<.001$} & 51.5 & \multirow{2}{*}{$<.001$} \\
\hline Some college and above & 59.8 & & 55.6 & & 48.5 & \\
\hline \multicolumn{7}{|l|}{ Marital status } \\
\hline Married & 55.3 & \multirow{3}{*}{$<.001$} & 57.6 & \multirow{3}{*}{$<.001$} & 56.1 & \multirow{3}{*}{$<.001$} \\
\hline Never married & 23.7 & & 15.0 & & 11.9 & \\
\hline Other ${ }^{m}$ & 21.0 & & 27.3 & & 32.1 & \\
\hline \multicolumn{7}{|l|}{ Sex } \\
\hline Male & 50.5 & \multirow{2}{*}{.19} & 49.0 & \multirow{2}{*}{$<.001$} & 52.8 & \multirow{2}{*}{$<.001$} \\
\hline Female & 49.5 & & 51.0 & & 47.2 & \\
\hline \multicolumn{7}{|l|}{ Race/ethnicity } \\
\hline White non-Hispanic & 68.1 & \multirow{3}{*}{$<.001$} & 70.5 & \multirow{3}{*}{$<.001$} & 62.6 & \multirow{3}{*}{$<.001$} \\
\hline Black non-Hispanic & 11.6 & & 15.2 & & 16.2 & \\
\hline Hispanic & 13.0 & & 7.6 & & 14.2 & \\
\hline
\end{tabular}

${ }^{a}$ Values reflect weighted percentages affirmative for condition or behavior.

${ }^{\mathrm{b}} P$ values based on Pearson $\mathrm{x}^{2}$ test of association; significant at $P<.05$.

${ }^{c}$ Prediabetes prevalence for 2015 is not included because a large number of states did not report on prediabetes.

${ }^{d}$ Ever been diagnosed with arthritis (eg, rheumatoid arthritis, gout, lupus, fibromyalgia).

${ }^{\mathrm{e}}$ Ever been diagnosed with any type of cancer.

${ }^{f}$ Ever been diagnosed with chronic heart disease, heart attack, or stroke.

${ }^{g}$ Ever been diagnosed with COPD or pulmonary disease.

${ }^{\mathrm{h}}$ Limited in any way in any activity because of physical, mental, or emotional problems.

${ }^{i}$ Body mass index $\left(\mathrm{BMI}, \mathrm{kg} / \mathrm{m}^{2}\right.$ ) is categorized as underweight (BMI <18.5), normal weight (BMI 18.5-24.9), overweight (BMI 25.0-30.0), or obese (BMI >30.0).

${ }^{j}$ Smoked more than 100 cigarettes during lifetime.

${ }^{\mathrm{k}}$ Men having more than 14 drinks per week and women having more than 7 drinks per week.

'During the past month, other than for your regular job, did you participate in any physical activities or exercises such as running, calisthenics, golf, gardening, or walking for exercise.

${ }^{m}$ Separated, widowed, never married, a member of an unmarried couple.

${ }^{n}$ Geographic regions based on United States Census (a detailed list of states included in each division is available at https://www2.census.gov/geo/pdfs/mapsdata/maps/reference/us_regdiv.pdf). 
(continued)

Table 2. Characteristics of Respondents That Have Ever Been Diagnosed with Prediabetes $(N=63,567)$ or Diabetes $(N=215,441)$, Behavioral Risk Factor Surveillance System, 2011-2015

\begin{tabular}{|c|c|c|c|c|c|c|}
\hline Characteristic & General Population, \% & $P$ Value $^{\mathrm{b}}$ & Prediabetes, \% & $P$ Value $^{\mathrm{b}}$ & Diabetes, \% & $P$ Value $^{\mathrm{b}}$ \\
\hline Other & 7.3 & & 6.6 & & 7.0 & \\
\hline \multicolumn{7}{|l|}{ Income, \$ } \\
\hline$<15,000$ & 11.5 & \multirow{5}{*}{$<.001$} & 12.7 & \multirow{5}{*}{$<.001$} & 18.2 & \multirow{5}{*}{$<.001$} \\
\hline 15,000 to $<25,000$ & 16.9 & & 19.3 & & 23.2 & \\
\hline 25,000 to $<35,000$ & 10.8 & & 12.1 & & 12.8 & \\
\hline 35,000 to $<50,000$ & 14.1 & & 15.2 & & 14.1 & \\
\hline$\geq 50,000$ & 46.6 & & 40.6 & & 31.7 & \\
\hline \multicolumn{7}{|l|}{ Health care access } \\
\hline Consistent access to health provider & 79.4 & $<.001$ & 88.3 & $<.001$ & 92.8 & $<.001$ \\
\hline Annual health checkup & 68.7 & $<.001$ & 79.2 & $<.001$ & 86.0 & $<.001$ \\
\hline \multicolumn{7}{|l|}{ Age, y } \\
\hline $18-34$ & 27.1 & \multirow{4}{*}{$<.001$} & 11.5 & \multirow{4}{*}{$<.001$} & 4.3 & \multirow{4}{*}{$<.001$} \\
\hline $35-49$ & 26.1 & & 22.3 & & 16.0 & \\
\hline $50-64$ & 28.1 & & 38.6 & & 40.1 & \\
\hline$\geq 65$ & 18.7 & & 27.6 & & 39.6 & \\
\hline \multicolumn{7}{|l|}{ Geographic region $^{\text {n }}$} \\
\hline Midwest: East North Central division & 16.1 & \multirow{9}{*}{$<.001$} & 16.5 & \multirow{9}{*}{$<.001$} & 15.9 & \multirow{9}{*}{$<.001$} \\
\hline Midwest: West North Central division & 6.8 & & 5.7 & & 6.1 & \\
\hline South: South Atlantic division & 19.8 & & 28.0 & & 21.1 & \\
\hline South: East South Central division & 5.8 & & 12.8 & & 7.0 & \\
\hline South: West South Central division & 11.3 & & 5.2 & & 12.6 & \\
\hline Northeast: New England division & 4.7 & & 4.7 & & 3.9 & \\
\hline Northeast: Middle Atlantic division & 12.9 & & 13.6 & & 12.5 & \\
\hline West: Mountain division & 7.1 & & 6.2 & & 6.1 & \\
\hline West: Pacific division & 15.6 & & 7.4 & & 14.8 & \\
\hline
\end{tabular}

a Values reflect weighted percentages affirmative for condition or behavior.

${ }^{\mathrm{b}} P$ values based on Pearson $\mathrm{x}^{2}$ test of association; significant at $P<.05$.

${ }^{c}$ Prediabetes prevalence for 2015 is not included because a large number of states did not report on prediabetes.

d Ever been diagnosed with arthritis (eg, rheumatoid arthritis, gout, lupus, fibromyalgia).

${ }^{\mathrm{e}}$ Ever been diagnosed with any type of cancer.

${ }^{f}$ Ever been diagnosed with chronic heart disease, heart attack, or stroke.

${ }^{g}$ Ever been diagnosed with COPD or pulmonary disease.

${ }^{\mathrm{h}}$ Limited in any way in any activity because of physical, mental, or emotional problems.

i Body mass index (BMI, kg/m²) is categorized as underweight (BMI <18.5), normal weight (BMI 18.5-24.9), overweight (BMI 25.0-30.0), or obese (BMI >30.0).

${ }^{j}$ Smoked more than 100 cigarettes during lifetime.

${ }^{\mathrm{k}}$ Men having more than 14 drinks per week and women having more than 7 drinks per week.

' During the past month, other than for your regular job, did you participate in any physical activities or exercises such as running, calisthenics, golf, gardening, or walking for exercise.

${ }^{\mathrm{m}}$ Separated, widowed, never married, a member of an unmarried couple.

${ }^{n}$ Geographic regions based on United States Census (a detailed list of states included in each division is available at https://www2.census.gov/geo/pdfs/mapsdata/maps/reference/us_regdiv.pdf).

The opinions expressed by authors contributing to this journal do not necessarily reflect the opinions of the U.S. Department of Health and Human Services, the Public Health Service, the Centers for Disease Control and Prevention, or the authors' affiliated institutions. 
Table 3. Logistic Regression Model and Estimate of Maximum Likelihood for Prediabetes and Diabetes, Adjusting for Health Conditions, Lifestyle, and Demographics, Behavioral Risk Factor Surveillance System, 2011-2015

\begin{tabular}{|c|c|c|c|c|}
\hline Characteristic & Prediabetes AOR $(95 \% \mathrm{Cl})$ & Diabetes AOR (95\% Cl) & $\begin{array}{l}\text { Prediabetes Max } \\
\text { Likelihood }\end{array}$ & Diabetes Max Likelihood \\
\hline \multicolumn{5}{|l|}{ Survey year } \\
\hline 2011 & \multicolumn{4}{|r|}{1 [Reference] } \\
\hline 2012 & $2.43(2.29-2.58)$ & $1.03(1.00-1.07)$ & 4.44 & 0.15 \\
\hline 2013 & $2.71(2.56-2.87)$ & $1.03(1.00-1.07)$ & 4.89 & 0.15 \\
\hline 2014 & $3.48(3.30-3.67)$ & $1.05(1.02-1.09)$ & 6.18 & 0.25 \\
\hline 2015 & $-{ }^{a}$ & $1.05(1.02-1.09)$ & $-{ }^{a}$ & 0.25 \\
\hline \multicolumn{5}{|c|}{ Health Condition } \\
\hline \multicolumn{5}{|l|}{ Chronic condition } \\
\hline Arthritis $^{\mathrm{b}}$ & $1.20(1.16-1.24)$ & $1.04(1.02-1.07)$ & 0.97 & 0.22 \\
\hline Depressive disorder & $1.36(1.31-1.41)$ & $1.11(1.08-1.14)$ & 1.44 & 0.50 \\
\hline Asthma & $1.14(1.09-1.20)$ & $1.10(1.06-1.13)$ & 0.56 & 0.38 \\
\hline Cancer $^{\mathrm{C}}$ & $1.10(1.05-1.14)$ & $0.94(0.91-0.96)$ & 0.36 & -0.25 \\
\hline Cardiovascular disease $^{d}$ & $1.06(1.01-1.10)$ & $1.56(1.52-1.60)$ & 0.19 & 1.53 \\
\hline $\begin{array}{l}\text { Chronic obstructive pulmonary disease } \\
\text { (COPD) }^{\mathrm{e}}\end{array}$ & $1.13(1.07-1.20)$ & $0.92(0.88-0.95)$ & 0.38 & -0.27 \\
\hline Kidney disease & $0.84(0.78-0.91)$ & $1.97(1.88-2.06)$ & -0.34 & 1.35 \\
\hline Limited activity ${ }^{f}$ & $1.08(1.04-1.13)$ & $1.07(1.05-1.10)$ & 0.40 & 0.35 \\
\hline \multicolumn{5}{|l|}{ General health } \\
\hline Excellent, Very Good & \multicolumn{4}{|r|}{1 [Reference] } \\
\hline Good, Fair & $1.38(1.33-1.43)$ & $2.89(2.81-2.97)$ & 1.94 & 6.44 \\
\hline Poor & $1.18(1.09-1.27)$ & $4.78(4.56-5.01)$ & 0.42 & 4.04 \\
\hline \multicolumn{5}{|l|}{$\mathrm{BMI}^{\mathrm{g}}$} \\
\hline Underweight & $0.96(0.82-1.13)$ & $0.69(0.60-0.80)$ & -0.06 & -0.59 \\
\hline Normal & \multicolumn{4}{|r|}{1 [Reference] } \\
\hline
\end{tabular}

Abbreviations: AOR, adjusted odds ratio; $\mathrm{Cl}$, confidence interval.

${ }^{a}$ Prediabetes prevalence for 2015 is not included because of large number of states not reporting on prediabetes.

${ }^{\mathrm{b}}$ Ever been diagnosed with arthritis (eg, rheumatoid arthritis, gout, lupus, fibromyalgia).

${ }^{\mathrm{c}}$ Ever been diagnosed with any type of cancer.

${ }^{d}$ Ever been diagnosed with chronic heart disease, heart attack, or stroke.

${ }^{\mathrm{e}}$ Ever been diagnosed with COPD or pulmonary disease.

${ }^{f}$ Limited in any way in any activity because of physical, mental, or emotional problems.

${ }^{\mathrm{g}}$ Body mass index (BMI, $\mathrm{kg} / \mathrm{m}^{2}$ ) is categorized as underweight (BMI <18.5), normal weight (BMI 18.5-24.9), overweight (BMI 25.0-30.0), or obese (BMI >30.0).

${ }^{\mathrm{h}}$ Smoked more than 100 cigarettes during lifetime.

'Men having more than 14 drinks per week and women having more than 7 drinks per week.

${ }^{j}$ During the past month, other than for your regular job, did you participate in any physical activities or exercises such as running, calisthenics, golf, gardening, or walking for exercise.

${ }^{k}$ Separated, widowed, never married, a member of an unmarried couple.

' Geographic regions based on United States Census (a detailed list of states included in each division is available at https://www2.census.gov/geo/pdfs/mapsdata/maps/reference/us_regdiv.pdf). 
(continued)

Table 3. Logistic Regression Model and Estimate of Maximum Likelihood for Prediabetes and Diabetes, Adjusting for Health Conditions, Lifestyle, and Demographics, Behavioral Risk Factor Surveillance System, 2011-2015

\begin{tabular}{|c|c|c|c|c|}
\hline Characteristic & Prediabetes AOR $(95 \% \mathrm{Cl})$ & Diabetes AOR (95\% Cl) & $\begin{array}{l}\text { Prediabetes Max } \\
\text { Likelihood }\end{array}$ & Diabetes Max Likelihood \\
\hline Overweight & $1.61(1.54-1.68)$ & $1.77(1.71-1.83)$ & 2.79 & 3.36 \\
\hline Obese & $2.47(2.36-2.58)$ & $3.66(3.55-3.78)$ & 5.04 & 7.24 \\
\hline \multicolumn{5}{|l|}{ Lifestyle } \\
\hline Smoking ${ }^{\text {h }}$ & $1.13(1.10-1.17)$ & $1.02(1.00-1.05)$ & 0.75 & 0.14 \\
\hline Consume alcohol regularly ${ }^{i}$ & $1.02(0.96-1.10)$ & $0.55(0.51-0.58)$ & 0.07 & -1.82 \\
\hline Exercise regularly $^{j}$ & $1.04(1.00-1.08)$ & $0.91(0.88-0.93)$ & 0.19 & -0.52 \\
\hline \multicolumn{5}{|c|}{ Demographics/socioeconomics } \\
\hline \multicolumn{5}{|l|}{ Military status } \\
\hline Veteran & $1.08(1.04-1.13)$ & $1.07(1.04-1.11)$ & 0.32 & 0.29 \\
\hline Nonveteran & & & & 1 [Reference] \\
\hline \multicolumn{5}{|l|}{ Education level } \\
\hline High school graduate or less & & & & 1 [Reference] \\
\hline Some college and above & $1.02(0.99-1.06)$ & $0.99(0.96-1.01)$ & 0.13 & -0.09 \\
\hline \multicolumn{5}{|l|}{ Marital status } \\
\hline Married & & & & 1 [Reference] \\
\hline Never married & $0.96(0.91-1.02)$ & $1.00(0.96-1.04)$ & -0.22 & -0.01 \\
\hline Other ${ }^{k}$ & $0.98(0.95-1.02)$ & $0.95(0.92-0.97)$ & -0.08 & -0.26 \\
\hline \multicolumn{5}{|l|}{ Sex } \\
\hline Male & & & & 1 [Reference] \\
\hline Female & $1.01(0.98-1.05)$ & $0.79(0.77-0.81)$ & 0.08 & -1.48 \\
\hline \multicolumn{5}{|l|}{ Race/ethnicity } \\
\hline White non-Hispanic & & & & 1 [Reference] \\
\hline Black non-Hispanic & $1.14(1.08-1.20)$ & $1.47(1.42-1.52)$ & 0.52 & 1.51 \\
\hline Hispanic & $0.84(0.78-0.92)$ & $1.51(1.45-1.58)$ & -0.70 & 1.71 \\
\hline
\end{tabular}

Abbreviations: $\mathrm{AOR}$, adjusted odds ratio; $\mathrm{Cl}$, confidence interval.

${ }^{a}$ Prediabetes prevalence for 2015 is not included because of large number of states not reporting on prediabetes.

${ }^{\mathrm{b}}$ Ever been diagnosed with arthritis (eg, rheumatoid arthritis, gout, lupus, fibromyalgia).

${ }^{\mathrm{c}}$ Ever been diagnosed with any type of cancer.

${ }^{d}$ Ever been diagnosed with chronic heart disease, heart attack, or stroke.

ever been diagnosed with COPD or pulmonary disease.

${ }^{f}$ Limited in any way in any activity because of physical, mental, or emotional problems.

${ }^{\mathrm{g}}$ Body mass index (BMI, $\mathrm{kg} / \mathrm{m}^{2}$ ) is categorized as underweight (BMI <18.5), normal weight (BMI 18.5-24.9), overweight (BMI 25.0-30.0), or obese (BMI >30.0).

${ }^{\mathrm{h}}$ Smoked more than 100 cigarettes during lifetime.

'Men having more than 14 drinks per week and women having more than 7 drinks per week.

${ }^{j}$ During the past month, other than for your regular job, did you participate in any physical activities or exercises such as running, calisthenics, golf, gardening, or walking for exercise.

${ }^{k}$ Separated, widowed, never married, a member of an unmarried couple.

' Geographic regions based on United States Census (a detailed list of states included in each division is available at https://www2.census.gov/geo/pdfs/mapsdata/maps/reference/us_regdiv.pdf).

The opinions expressed by authors contributing to this journal do not necessarily reflect the opinions of the U.S. Department of Health and Human Services, the Public Health Service, the Centers for Disease Control and Prevention, or the authors' affiliated institutions. 
(continued)

Table 3. Logistic Regression Model and Estimate of Maximum Likelihood for Prediabetes and Diabetes, Adjusting for Health Conditions, Lifestyle, and Demographics, Behavioral Risk Factor Surveillance System, 2011-2015

\begin{tabular}{|c|c|c|c|c|}
\hline Characteristic & Prediabetes AOR $(95 \% \mathrm{Cl})$ & Diabetes AOR (95\% Cl) & $\begin{array}{l}\text { Prediabetes Max } \\
\text { Likelihood }\end{array}$ & Diabetes Max Likelihood \\
\hline Other & $1.38(1.29-1.48)$ & $1.61(1.52-1.71)$ & 1.03 & 1.53 \\
\hline \multicolumn{5}{|l|}{ Income, \$ } \\
\hline$<15,000$ & \multicolumn{4}{|r|}{1 [Reference] } \\
\hline 15,000 to $<25,000$ & $1.09(1.02-1.16)$ & $0.91(0.88-0.95)$ & 0.38 & -0.44 \\
\hline 25,000 to $<35,000$ & $1.11(1.04-1.19)$ & $0.83(0.79-0.86)$ & 0.40 & -0.73 \\
\hline 35,000 to $<50,000$ & $1.10(1.03-1.18)$ & $0.75(0.71-0.78)$ & 0.42 & -1.26 \\
\hline$\geq 50,000$ & $1.01(0.95-1.08)$ & $0.66(0.63-0.69)$ & 0.09 & -2.57 \\
\hline \multicolumn{5}{|l|}{ Health care access } \\
\hline Consistent access to health provider & $0.81(0.76-0.86)$ & $0.53(0.51-0.56)$ & -1.06 & -3.13 \\
\hline Annual health checkup & $0.82(0.79-0.86)$ & $0.54(0.53-0.56)$ & -1.13 & -3.47 \\
\hline \multicolumn{5}{|l|}{ Age, y } \\
\hline $18-34$ & \multicolumn{4}{|r|}{1 [Reference] } \\
\hline $35-49$ & $1.61(1.50-1.73)$ & $2.91(2.73-3.11)$ & 2.56 & 5.77 \\
\hline $50-64$ & $2.23(2.08-2.39)$ & $6.21(5.82-6.62)$ & 4.42 & 10.08 \\
\hline$\geq 65$ & $2.28(2.12-2.46)$ & $9.46(8.85-10.1)$ & 3.95 & 10.75 \\
\hline \multicolumn{5}{|l|}{ Geographic region' } \\
\hline Midwest: East North Central division & \multicolumn{4}{|r|}{1 [Reference] } \\
\hline Midwest: West North Central division & $0.85(0.79-0.90)$ & $0.99(0.96-1.03)$ & -0.51 & -0.03 \\
\hline South: South Atlantic division & $1.43(1.36-1.51)$ & $1.05(1.02-1.09)$ & 1.76 & 0.26 \\
\hline South: East South Central division & $2.13(2.01-2.26)$ & $1.10(1.05-1.14)$ & 2.17 & 0.26 \\
\hline South: West South Central division & $0.46(0.42-0.50)$ & $1.12(1.07-1.17)$ & -3.02 & 0.44 \\
\hline Northeast: New England division & $1.03(0.97-1.07)$ & $0.94(0.91-0.98)$ & 0.07 & -0.16 \\
\hline Northeast: Middle Atlantic division & $1.07(1.00-1.14)$ & $0.97(0.93-1.01)$ & 0.27 & -0.14 \\
\hline West: Mountain division & $0.96(0.90-1.03)$ & $1.01(0.97-1.05)$ & -0.12 & 0.03 \\
\hline West: Pacific division & $0.51(0.48-0.54)$ & $1.08(1.03-1.13)$ & -3.01 & 0.33 \\
\hline
\end{tabular}

Abbreviations: AOR, adjusted odds ratio; $\mathrm{Cl}$, confidence interval.

${ }^{\text {a }}$ Prediabetes prevalence for 2015 is not included because of large number of states not reporting on prediabetes.

${ }^{b}$ Ever been diagnosed with arthritis (eg, rheumatoid arthritis, gout, lupus, fibromyalgia).

${ }^{c}$ Ever been diagnosed with any type of cancer.

${ }^{\mathrm{d}}$ Ever been diagnosed with chronic heart disease, heart attack, or stroke.

e Ever been diagnosed with COPD or pulmonary disease.

${ }^{f}$ Limited in any way in any activity because of physical, mental, or emotional problems.

${ }^{\mathrm{g}}$ Body mass index (BMI, $\mathrm{kg} / \mathrm{m}^{2}$ ) is categorized as underweight (BMI <18.5), normal weight (BMI 18.5-24.9), overweight (BMI 25.0-30.0), or obese (BMI >30.0).

${ }^{\mathrm{h}}$ Smoked more than 100 cigarettes during lifetime.

Men having more than 14 drinks per week and women having more than 7 drinks per week.

${ }^{j}$ During the past month, other than for your regular job, did you participate in any physical activities or exercises such as running, calisthenics, golf, gardening, or walking for exercise.

${ }^{\mathrm{k}}$ Separated, widowed, never married, a member of an unmarried couple.

' Geographic regions based on United States Census (a detailed list of states included in each division is available at https://www2.census.gov/geo/pdfs/mapsdata/maps/reference/us_regdiv.pdf).

The opinions expressed by authors contributing to this journal do not necessarily reflect the opinions of the U.S. Department of Health and Human Services, the Public Health Service, the Centers for Disease Control and Prevention, or the authors' affiliated institutions. 